\title{
Effects of aromatase inhibitors on proliferation and apoptosis in eutopic endometrial cell cultures from patients with endometriosis
}

\author{
Gabriela F. Meresman, Ph.D., ${ }^{\mathrm{a}}$ Mariela Bilotas, M.Sc., ${ }^{\mathrm{a}}$ Verónica Abello, M.Sc., ${ }^{\mathrm{a}}$ \\ Ricardo Buquet, M.D., Ph.D., ${ }^{\mathrm{b}}$ Marta Tesone, Ph.D., ${ }^{\mathrm{a}}$ and Carlos Sueldo, M.D. ${ }^{\mathrm{c}}$

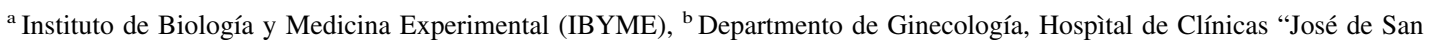 \\ Martín," and " Centro de Estudios en Giencología y Reproducción (CEGyR), Buenos Aires, Argentina
}

Objective: To study the effect of letrozole (Let) and anastrozole (Anas) on apoptosis and cell proliferation in epithelial endometrial cells (EEC) from patients with endometriosis (EDT).

Design: Prospective study.

Setting: Research institute and clinical fertility center.

Patient(s): Eighteen women with untreated EDT.

Intervention(s): Biopsy specimens of eutopic endometrium were obtained from all subjects. Apoptosis and cell proliferation were examined in EEC after incubation with Let or Anas.

Main Outcome Measure(s): Percentage of apoptotic cells $(\mathrm{ApC})$ was evaluated by the acridine orange-ethidium bromide technique; cell proliferation was assessed by ${ }^{3} \mathrm{H}$-thymidine incorporation.

Result(s): Treatment with Let $10 \mathrm{nM}$ and Let $100 \mathrm{nM}$ enhanced values of ApC in cultures from EDT patients. Epithelial endometrial cells treated with Anas $100 \mathrm{nM}$ or Anas $500 \mathrm{nM}$ showed a statistically significant induction on apoptosis levels. Cultures treated with Let $1 \mathrm{nM}$ or Anas $50 \mathrm{nM}$ did not show any significant differences in ApC levels compared with basal conditions. ${ }^{3} \mathrm{H}$-Thymidine uptake was down regulated by Let $10 \mathrm{nM}$ and Let $100 \mathrm{nM}$. Similarly, Anas $100 \mathrm{nM}$ and Anas $500 \mathrm{nM}$ showed a significantly lower degree of cell proliferation in EEC. Lower concentrations of Let and Anas did not induce any significant change in cell proliferation rates. Conclusion(s): Our results show that Let and Anas produced a significant and positive effect on apoptosis and cell proliferation on EEC from EDT patients. These findings support the further investigation of aromatase inhibitors as a treatment option in EDT. (Fertil Steril ${ }^{\circledR} 2005 ; 84: 459-63$. $\odot 2005$ by American Society for Reproductive Medicine.)

Key Words: Aromatase inhibitors, endometriosis, endometrial epithelial cells, apoptosis, cell proliferation

Endometriosis, defined as the presence of endometrial glands and stroma outside the uterine cavity, is a prevalent disease in women during reproductive years. Although its etiology is still controversial, the eutopic endometrium has been the focus of intensive research because it appears to be the source of the tissue ultimately responsible for the presence of peritoneal implants that characterize the pelvic endometriosis (1).

Our group has demonstrated the presence of abnormalities in the eutopic endometrium from patients with endometriosis, mainly manifested by a decreased degree of apoptosis and increased cell proliferation, both at the glandular epithelium and stromal levels, in comparison with eutopic endometrium from patients without the disease $(2,3)$.

Because endometriosis is an E-dependent disorder, aromatase expression in the eutopic endometrium as well as in

Received August 5, 2004; revised and accepted January 27, 2005.

Supported by the National Agency for Promotion of Science and Technology (PICT 6384 BID 1201 OC-AR) and PLACIRH (Latin-American Program for Instruction and Research in Human Reproduction).

Reprint requests: Gabriela Meresman, Ph.D., Instituto de Biología y Medicina Experimental, Vuelta de Obligado 2490, Buenos Aires (1428), Argentina (FAX: 541-1-47862564; E-mail: meresman@dna.uba.ar). the endometriotic implants would be of paramount importance in the development and growth of endometriosis (4).

Aromatase p-450 is the key enzyme for E biosynthesis, because the conversion of androstenedione and $\mathrm{T}$ to estrone and $\mathrm{E}_{2}$ is catalyzed by aromatase. Bulun et al. (5) described the aromatase activity expressed in the human ovary as well as in extraglandular sites; this group also reported on the local $\mathrm{E}$ production by aromatization of androgens, which in turn activates the cyclo-oxygenase type 2 enzyme to produce prostaglandin $E_{2}$ from arachidonic acid. Prostaglandin $E_{2}$ has been shown to be one of the most potent inducers of aromatase activity in endometriotic stromal cells $(5,6)$, establishing a positive feedback loop in favor of continuous $\mathrm{E}$ formation in endometriosis lesions.

Aromatase expression is consistently found in endometriosis lesions and in the eutopic endometrium from patients with endometriosis, whereas it is absent in eutopic endometrium from patients without the disease $(5,6)$. Recently, Dheenadayalu et al. (7) evaluated the expression of aromatase p-450 mRNA by using RT-PCR and reported that a small percentage of patients with endometriosis do not show aromatase activity in the eutopic endometrium, and con- 
versely, a small percentage of patients without endometriosis show expression of the enzyme at the endometrial level.

Takayama et al. (8) first reported on the therapeutic role of the aromatase inhibitor anastrazole in the successful treatment of a postmenopausal patient with an endometriotic pelvic mass (after total abdominal hysterectomy and bilateral salpingo-oophorectomy) that had failed to respond to other forms of medical therapy commonly used for endometriosis. More recently, Ailawadi et al. (9) reported on the use of another aromatase inhibitor, letrozole, combined with norethindrone acetate in patients with endometriosis, showing an effective resolution of the endometriosis lesions as documented by posttreatment laparoscopy.

Given the significance of aromatase activity in the $\mathrm{E}$ production cycle described above, in endometriosis lesions, and in the eutopic endometrium from patients with endometriosis, our objective in this study was to evaluate the in vitro effects of the potent aromatase inhibitors letrozole and anastrazole, nonsteroidal reversible competitive inhibitors, on the proliferation and apoptosis in epithelial endometrial cell cultures obtained from eutopic endometrial biopsies in patients with endometriosis.

\section{MATERIALS AND METHODS Patients}

A total of 18 patients who underwent diagnostic laparoscopy under general anesthesia participated in this study: all of them had untreated endometriosis (stages I and II). Determination of the stage of the disease was performed according to the revised American Fertility Society classification (10). All patients in the study were infertile, showed regular menstrual cycles, and had not received any hormonal medical treatment for endometriosis during the previous 6 months. Biopsy specimens of eutopic endometrium were obtained with a Novak curette (Bioteque America, Inc., Langhorne, PA) from all subjects during the proliferative phase, as described elsewhere (2).

This study was approved by the Ethics and Research Committee of the Biology and Experimental Medicine Institute, and all subjects included in the study signed informed consents.

\section{Endometrial Cell Cultures}

The tissue was immediately placed into culture medium and was processed within 60 minutes after collection. Epithelial cells were enzymatically separated, isolated by successive centrifugation, and primary cultures were established for in vitro studies on implantation by using a modification of a method described by Bongso et al. (11) and Meresman et al. (12).

Briefly, the explant was minced, washed, and placed in basic medium (MEM D-Val; Gibco, Paisley, United Kingdom) containing $100 \mathrm{IU} / \mathrm{mL}$ of penicillin, $100 \mu \mathrm{g} / \mathrm{mL}$ of streptomycin, and $25 \mu \mathrm{g} / \mathrm{mL}$ of amphotericin B (Gibco) with
$1 \mathrm{mg} / \mathrm{mL}$ of collagenase (Gibco, type I). After 2 hours' incubation at $37^{\circ} \mathrm{C}$ in an atmosphere of $5 \% \mathrm{CO}_{2}$, the resulting suspension was processed by centrifuge at $100 \times g$ for 5 minutes. The pellet containing glands was resuspended in nutrient medium and spun again at $100 \times g$ for 5 minutes. The final pellet mainly contained epithelial cells. After a 1-hour incubation, the medium containing enriched epithelial cells was removed and plated in fresh medium. The cells were cultured in quadruplicate for each patient, with $10 \%$ fetal bovine serum (FBS, Gibco).

Epithelial cell cultures were left undisturbed at $37^{\circ} \mathrm{C}$ for 2 days. Subsequently, the cells were washed and incubated with $2.5 \%$ FBS medium for 48 additional hours.

\section{Cell Proliferation Assay}

Fifty thousand epithelial endometrial cells were plated in 96-microwell plates and incubated with $10 \%$ FBS medium. After 48 hours' incubation, the cells were washed, and different agents were added to supplemented 2.5\% FBS medium: letrozole (Femara; Novartis, Basel, Switzerland) in concentrations of $0.1,1,10$, and $100 \mathrm{nM}$ and anastrozole (Arimidex; Astra Zeneca, Cheshire, United Kingdom) in concentrations of $1,10,50,100$, and $500 \mathrm{nM}$. The cells were incubated with the agents for 48 additional hours.

Twenty-four hours before harvesting, $1 \mu \mathrm{Ci}{ }^{3} \mathrm{H}$-thymidine (Nen, Dupont, Boston, MA) was added to each microwell, and DNA synthesis was assessed by ${ }^{3} \mathrm{H}$-thymidine incorporation with a liquid scintillation counter (13).

\section{Apoptosis Assay}

The percentage of apoptotic cells was assessed by the acridine orange-ethidium bromide technique (12) in endometrial cultures at basal conditions and after exposure to letrozole $(1,10$, and $100 \mathrm{nM})$ or anastrozole $(50,100$, or $500 \mathrm{nM})$.

Acridine orange is a vital dye that is excluded from viable cells. It is specific for apoptotic forms of cell death and does not significantly label cells undergoing necrotic death caused by injury (14). After addition of the acridine orange (4 $\mu \mathrm{g} / \mathrm{ml}$ )-ethidium bromide (4 $\mu \mathrm{g} / \mathrm{ml})$ mix, the cells were observed under fluorescence microscopy, and the apoptotic cells were counted and expressed as a percentage of the total.

\section{Statistics}

Statistical comparisons were performed by Kruskal-Wallis nonparametric analysis of variance (ANOVA) test, followed by Dunn's multiple comparison test. Regardless of the statistical test, only a $P$ value of $\leq .05$ was considered significant.

\section{RESULTS}

\section{Effects of Aromatase Inhibitors on Epithelial Cell Proliferation}

The effects of different concentrations of letrozole on epithelial cell proliferation are displayed in Figure 1. We found 


\section{FIGURE 1}

Effects of letrozole on cell proliferation in endometrial cell cultures from subjects with endometriosis. Epithelial cell cultures from patients with endometriosis were analyzed for cell proliferation by ${ }^{3} \mathrm{H}$-thymidine incorporation after exposure to increasing concentrations of letrozole. Values are expressed as percentage of basal cell proliferation set as $100 \%$ (without letrozole). ${ }^{\star} P<.05$ vs. basal; ${ }^{\star \star} P<.001$ vs. basal.

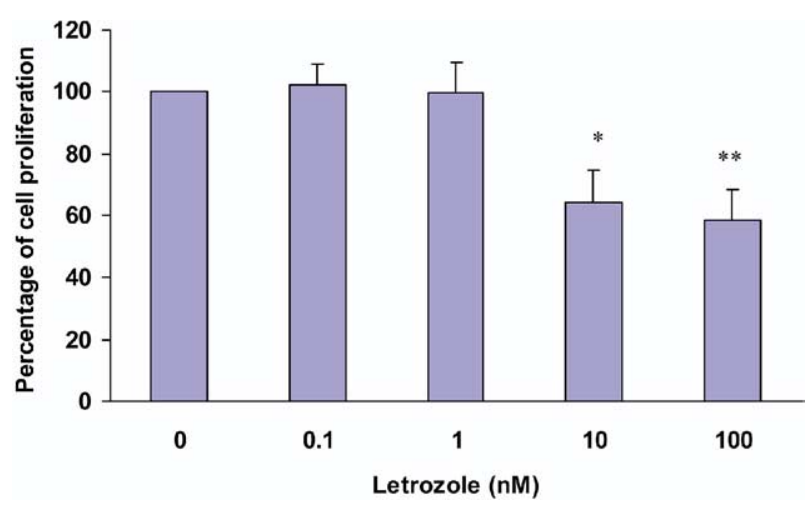

Meresman. Aromatase inhibition and endometriosis. Fertil Steril 2005.

that in endometrial cultures from patients with endometriosis, letrozole at low concentrations had no effect on basal DNA synthesis: $102.3 \% \pm 6.9 \%$ and $99.7 \% \pm 6.9 \%$ in letrozole $0.1 \mathrm{nM}-$ and $1 \mathrm{nM}$-stimulated cultures, respectively (results expressed as a percentage of basal conditions, $P>.05$, not statistically significant).

In contrast, after exposure to higher concentrations of letrozole, the epithelial endometrial cultures showed a significantly lower degree of cell proliferation: $64.4 \% \pm 10.7 \%$ in letrozole $10 \mathrm{nM}-$ stimulated cultures $(P<.05$ vs. basal $)$ and $58.2 \% \pm 10.2 \%$ in letrozole $100 \mathrm{nM}$-stimulated cultures $(P<.001$ vs. basal). The results also are expressed as a percentage of basal conditions (Fig. 1).

In endometrial cultures from endometriosis patients, ${ }^{3} \mathrm{H}$ thymidine uptake was down-regulated by anastrozole 100 $\mathrm{nM}$ and $500 \mathrm{nM}: 47.3 \% \pm 9.7 \%$ and $36.0 \% \pm 7.2 \%$, respectively, expressed as a percentage of basal conditions $(P<.01$ and $P<.001$ vs. basal, respectively; Fig. 2). Lower concentrations of anastrozole had no significant effect on basal cell proliferation: $89.8 \% \pm 7.1 \% ; 73.5 \% \pm 9.6 \%$, and $65.0 \% \pm 9.9 \%$ in anastrozole $1 \mathrm{nM}, 10 \mathrm{nM}$, and $50 \mathrm{nM}-$ stimulated cultures, respectively $(P>.05$, not significant; Fig. 2).

\section{Effects of Aromatase Inhibitors on Epithelial Cell Apoptosis}

Exposure to letrozole $10 \mathrm{nM}$ and $100 \mathrm{nM}$ significantly increased the level of apoptosis in cultures from patients with endometriosis. Letrozole $10 \mathrm{nM}$ showed an effect on endometrial growth, enhancing apoptosis in endometrial cultures from patients with endometriosis from $14.6 \% \pm 1.9 \%$ to $34.6 \% \pm 6.7 \%$ (expressed as percentage of apoptotic cells, $P<.05$ vs. basal), and letrozole $100 \mathrm{nM}$ from $14.6 \% \pm 1.9 \%$ to $45.3 \% \pm 6.9 \%(P<.001$ vs. basal; Fig. 3$)$. In contrast, letrozole $1 \mathrm{nM}$ had no effect on basal apoptosis: $21.3 \% \pm$ $3.3 \%$ ( $P>.05$ vs. basal, not significant; Fig. 3).

Anastrozole, $100 \mathrm{nM}$ and $500 \mathrm{nM}$, showed a significant effect on endometrial apoptosis, enhancing the apoptosis levels from $17.5 \% \pm 1.4 \%$ to $41.9 \% \pm 6.9 \%(P<.05$ vs basal) and from $17.5 \% \pm 1.4 \%$ to $53.8 \% \pm 7.9 \%$, respectively (expressed as percentage of apoptotic cells, $P<.001$ vs. basal). In contrast, anastrozole $50 \mathrm{nM}$ had no significant effect on basal apoptosis: $31.0 \% \pm 2.9 \%$ ( $P>.05$ vs. basal, not significant; Fig. 4).

\section{DISCUSSION}

After the significant role of aromatase in the pathophysiology in endometriosis was explored and reported by Bulun et al. $(5,6)$ and Takayama et al. (8), other investigators focused on different aspects of this association. A recent study by Fazleabas et al. (15) showed in experimentally induced endometriotic lesions in baboons that the expression of aromatase was consistently found in endometriosis lesions as well as in eutopic endometrium 10 months after the disease was surgically established (15). There is a body of experi-

\section{FIGURE 2}

Effects of anastrozole on cell proliferation in endometrial cell cultures from subjects with endometriosis. Epithelial cell cultures from patients with endometriosis were analyzed for cell proliferation by ${ }^{3} \mathrm{H}$-thymidine incorporation after exposure to increasing concentrations of anastrozole. Values are expressed as percentage of basal cell proliferation set as $100 \%$ (without anastrozole). ${ }^{* \star \star} P<.01$ vs. basal. ${ }^{* \star} P<.001$ vs. basal.

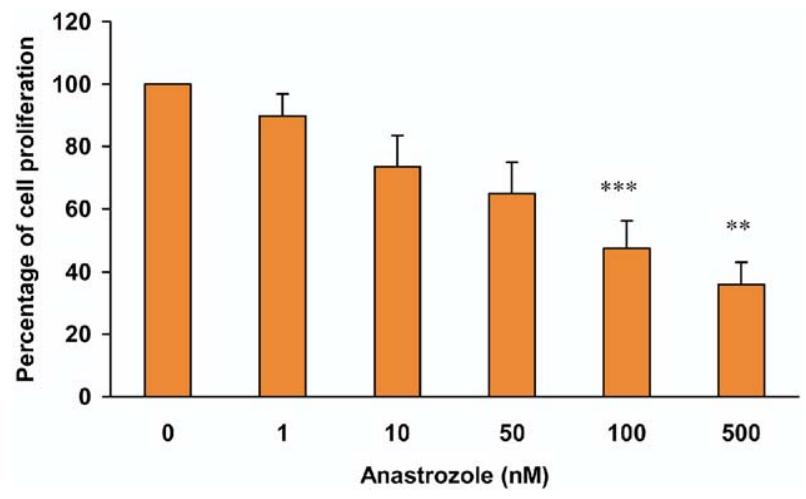

Meresman. Aromatase inhibition and endometriosis. Fertil Steril 2005. 


\section{FIGURE 3}

Effects of letrozole on apoptosis in endometrial cell cultures from subjects with endometriosis.

Epithelial cell cultures from patients with endometriosis were analyzed for apoptosis by the acridine orange-ethidium bromide technique at basal conditions and stimulated with letrozole in increasing concentrations. Values are expressed as percentage of apoptotic cells. The cells were viewed with a fluorescence microscope and the apoptotic cells were counted as a percentage of the total. ${ }^{\star} P<.05$ vs. basal. ${ }^{\star \star} P<.001$ vs. basal.

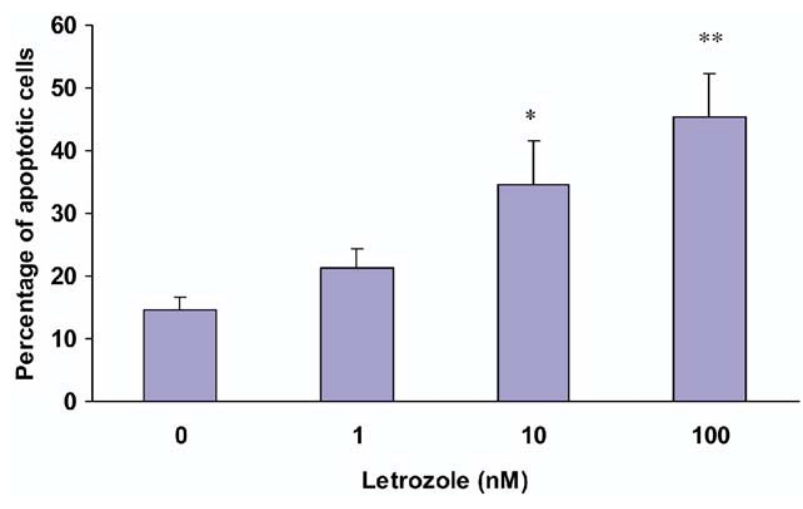

Meresman. Aromatase inhibition and endometriosis. Fertil Steril 2005.

mental evidence demonstrating the significance of aromatase expression in the initiation and growth of endometriosis $(5-7,16)$.

Zeitoun and Bulun (16) demonstrated that aromatase was a key molecule in the pathophysiology of endometriosis and that its inhibition may become a novel therapeutic strategy in the future through a more direct mechanism on the lesion itself, rather than by an indirect effect as commonly seen in medical therapy for endometriosis working mainly by creating a hypoestrogenic state (16).

The first report on aromatase inhibition in humans was that of Takayama et al. (8) in a menopausal patient. More recently, Razzi et al. (17) reported on using aromatase inhibition in a case of a young ovariectomized woman with endometriosis. In addition, Ailawadi et al. (9) published a pilot study on the successful treatment of endometriosis with a combination of letrozole and norethindrone acetate.

In this study, epithelial cell cultures of eutopic human endometrium were used in a model to evaluate cell proliferation and apoptosis in response to the addition of aromatase inhibitors. Although the cells employed in this investigation were not derived from endometriotic implants and their in vitro response may not be identical, the rationale for the use of endometrial cells in short-term culture as a model for endometriotic implants has been described elsewhere. This in vitro model allows to establish a correct parallelism with the endometriotic lesion performance $(18,19)$.
The results in our study support the role of aromatase p-450 inhibition in endometriosis, because the enzyme inhibition with letrozole or anastrozole was able to significantly suppress endometrial cell proliferation and increase the degree of apoptosis in epithelial endometrial cell cultures obtained from eutopic endometrial biopsies in endometriosis patients. Given the fact that aromatase p-450 overexpression also is consistently found in endometriosis lesions, it is tempting to speculate that similar findings in favorable tissue suppression and increased apoptosis can be expected to occur with aromatase inhibition in endometriosis lesions.

Kudoh et al. (20) and Fang et al. (21) demonstrated the effective role of aromatase inhibition in experimental endometriosis in rodents. In addition, there are preliminary data in humans that indicate that aromatase inhibition may be a novel therapeutic strategy in premenopausal patients (9) as well as in postmenopausal patients (8) with endometriosis.

Our findings, under in vitro culture conditions, are in agreement with those reported by Thiantanawat et al. (22) on human breast cancer cells. These investigators showed that aromatase inhibition in vitro produced a consistent growth suppression and cell cycle arrest, as well as an increase in apoptotic index, demonstrating correlating changes in proapoptotic proteins (increased Bax expression) and antiapoptotic proteins (decreased Bcl-2 expression). They also are in agreement with the findings of Mitropoulou et al. (23),

\section{FIGURE 4}

Effects of anastrozole on apoptosis in endometrial cell cultures from subjects with endometriosis. Epithelial cell cultures from patients with endometriosis were analyzed for apoptosis by the acridine orange-ethidium bromide technique at basal conditions and stimulated with anastrozole in increasing concentrations. Values are expressed as percentage of apoptotic cells. The cells were viewed by a fluorescence microscope and counted the apoptotic cells as percentage of the total. ${ }^{\star} P<.05$ vs. basal. ${ }^{\star \star} P<.001$ vs. basal.

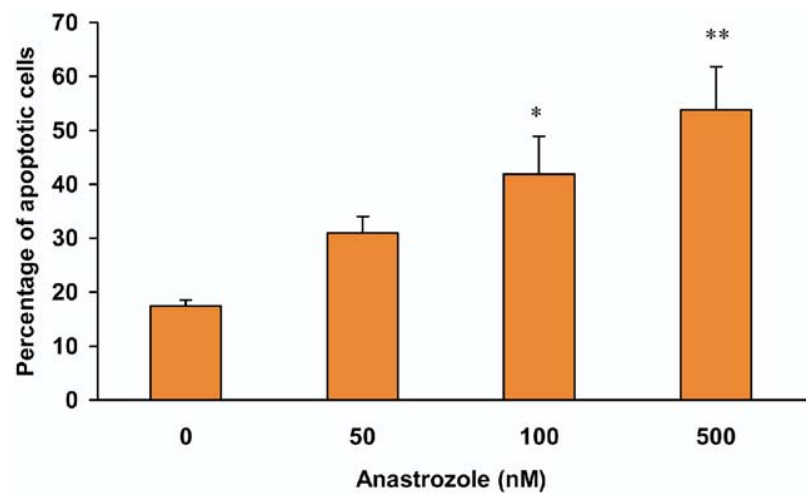

Meresman. Aromatase inhibition and endometriosis. Fertil Steril 2005. 
who in a similar in vitro system showed that aromatase inhibition with letrozole significantly suppressed the endogenous aromatase-induced proliferation of human epithelial breast cancer cells.

In summary, our study showed that aromatase inhibition, with a potent third-generation nonsteroidal compound in vitro, significantly decreased cell proliferation and increased the levels of apoptosis in eutopic endometrial cell cultures from patients with endometriosis. These data support the further investigation of aromatase inhibition as a novel therapeutic modality in endometriosis.

Acknowledgment: The authors thank AstraZeneca, United Kingdom, for providing the anastrozole (Arimidex).

\section{REFERENCES}

1. Sharpe-Timms KL. Endometrial anomalies in women with endometriosis. Ann NY Acad Sci 2001;943:131-47.

2. Meresman GF, Vighi S, Buquet RA, Contreras-Ortiz O, Tesone M, Rumi LS. Apoptosis and expression of Bcl-2 and Bax in eutopic endometrium from women with endometriosis. Fertil Steril 2000;74: $760-6$.

3. Meresman GF, Auge L, Baranao RI, Lombardi E, Tesone M, Sueldo C. Oral contraceptives suppress cell proliferation and enhance apoptosis of eutopic endometrial tissue from patients with endometriosis. Fertil Steril 2002;77:1141-7.

4. Kitawaki J, Kado N, Ishihara H, Koshiba H, Kitaoka Y, Honjo H. Endometriosis: the pathophysiology as an estrogen-dependent disease. J Steroid Biochem Mol Biol 2002;83:149-55.

5. Bulun SE, Fang Z, Imir G, Gurates B, Tamura M, Yilmaz B, et al. Aromatase and endometriosis. Semin Reprod Med 2004;22:45-50.

6. Bulun SE, Zeitoun KM, Takayama K, Sasano H. Estrogen biosynthesis in endometriosis: molecular basis and clinical relevance. J Mol Endocrinol 2000;25:35-42.

7. Dheenadayalu K, Mak I, Gordts S, Campo R, Higham J, Puttemans P, et al. Aromatase P450 messenger RNA expression in eutopic endometrium is not a specific marker for pelvic endometriosis. Fertil Steril 2002;78:825-9.

8. Takayama K, Zeitoun K, Gunby RT, Sasano H, Carr BR, Bulun SE. Treatment of severe postmenopausal endometriosis with an aromatase inhibitor. Fertil Steril 1998;69:709-13.

9. Ailawadi RK, Jobanputra S, Kataria M, Gurates B, Bulun SE. Treat- ment of endometriosis and chronic pelvic pain with letrozole and norethindrone acetate: a pilot study. Fertil Steril 2004;8:290-6.

10. American Fertility Society. Revised American Fertility Society classification of endometriosis. Fertil Steril 1985;43:351-2.

11. Bongso A, Gajra B, Lian NP, Wong PC, Soon-Chye N, Ratnam S. Establishment of human endometrial cell cultures. Hum Reprod 1988; 3:705-13.

12. Meresman GF, Bilotas M, Buquet RA, Baranao RI, Sueldo C, Tesone M. Gonadotropin-releasing hormone agonist induces apoptosis and reduces cell proliferation in eutopic endometrial cultures from women with endometriosis. Fertil Steril 2003;80(Suppl 2):702-7.

13. Meresman GF, Barañao RI, Tenenbaum A, Singla JJ, Neuspiller NR, Rumi LS. Effect of peritoneal fluid from patients with minimal and severe endometriosis on endometrial stromal cell proliferation. Arch Gynecol Obstet 1997;259:109-15.

14. Abrams JM, White K, Fessler LI, Steller H. Programmed cell death during Drosophila embryogenesis. Development 1993;117:29-43.

15. Fazleabas AT, Brudney A, Chai D, Langoi D, Bulun SE. Steroid receptor and aromatase expression in baboon endometriotic lesions. Fertil Steril 2003;80(Suppl 2):820-7.

16. Zeitoun KM, Bulun SE. Aromatase: a key molecule in the pathophysiology of endometriosis and a therapeutic target. Fertil Steril 1999;72: 961-9.

17. Razzi S, Fava A, Sartini A, De Simone S, Cobellis L, Petraglia F. Treatment of severe recurrent endometriosis with an aromatase inhibitor in a young ovariectomised woman. Br J Obstet Gynaecol 2004; 111:182-4.

18. Surrey ES, Halme J. Effect of peritoneal fluid from endometriosis patients on endometrial stromal cell proliferation in vitro. Obstet Gynecol 1990;76:792-7.

19. Fleming H. Structure and function of cultured endometrial epithelial cells. Semin Reprod Endocrinol 1999;17:93-106.

20. Kudoh M, Susaki Y, Ideyama Y, Nanya T, Mori M, Shikama H. Inhibitory effects of a novel aromatase inhibitor, YM511, on growth of endometrial explants and insulin-like growth factor-I gene expression in rats with experimental endometriosis. J Steroid Biochem Mol Biol 1997;63:75-80.

21. Fang Z, Yang S, Gurates B, Tamura M, Simpson E, Evans D, et al. Genetic or enzymatic disruption of aromatase inhibits the growth of ectopic uterine tissue. J Clin Endocrinol Metab 2002;87:3460-6.

22. Thiantanawat A, Long BJ, Brodie AM. Signaling pathways of apoptosis activated by aromatase inhibitors and antiestrogens. Cancer Res 2003; 63:8037-50.

23. Mitropoulou TN, Tzanakakis GN, Kletsas D, Kalofonos HP, Karamanos NK. Letrozole as a potent inhibitor of cell proliferation and expression of metalloproteinases (MMP-2 and MMP-9) by human epithelial breast cancer cells. Int J Cancer 2003;104:155-60. 